\title{
The Effectiveness Test of Ultrasonic Extraction Microwave Distillation (USE-MD) Method in Capsaicin Extraction
}

\author{
Ach. Ferdiansyah Pradana $\mathrm{P}^{1}$, Moch. Dimas Khoirul $\mathrm{U}^{1}$, Angga Septian E ${ }^{1}$
}

\begin{abstract}
Chili (Capsicum frutescens) is one of foodstuffs whose price is fluctuate and still not processed well, so it becomes damaged. Processing chili becomes capsaicin extract can be done by using MAE method that requires high power and UAE method that produces low yield. Therefore, this study aimed to process chilies as capsaicin extract by using USE-MD and MEMD methods. Chilies were extracted using $500 \mathrm{ml}$ ethanol $96 \%$ in 10, 20, 30, 40 and 50 minutes. The operating condition of the distillation was $78^{\circ} \mathrm{C}$ with a pressure of $1 \mathrm{~atm}$. The result showed that the best method to get capcaisin extract was USE-MD method with optimum extraction time about 30 minutes. This method gave yield about $2.795 \%$ with concentration of capsaicin about $0.94 \pm 0.02 \% \mathrm{lb} / \mathrm{lb}$.
\end{abstract}

Keywords_Capsaicin; Microwave; Ultrasonic; Concentration and Yield.

\section{INTRODUCTION}

$\mathrm{C}$ ayenne pepper is one of the most popular foodstuff in Indonesia, because it is used in almost all Indonesian dishes. In 2014, cayenne pepper production was increasing about $4.04 \%$ and it is estimated to increase production in the next year [1]. However, the increase in productivity of cayenne pepper was not offset by stable market price, so it caused cayenne price was fluctuate and difficult to predict Beside that, data supply of all kinds of chili nationally in 2007 showed that untapped chili and damaged chili are nearly $33 \%$ of the total national production of chili [2]. From this problem, we need a solution to optimize the use of cayenne pepper in extract form (capsaicin), so a large harvest of chili does not decay.

Capsaicinoids as $\mathrm{N}$-vanillylamides of fatty acids are a group of pungent chemical analogues which are usually found in chili peppers [3]. Generally, there are two major capsaicinoids found in chili peppers, capsaicin and dihydrocapsaicin, which represent about $77-98 \%$ of total capsaicinoids content in peppers [4]. In addition to these two major capsaicinoids, other minor capsaicinoids are found in hot peppers, such as nordihydrocapsaicin, norcapsaicin, homocapsaicin, homodihydrocapsaicin, nornorcapsaicin, nornornorcapsaicin, and nonivamide [5]. Pungency of chili peppers is described by Scoville Heat Units (SHU). Capsaicinoid content is converted to SHU by multiplying the capsaicinoid concentration in parts per million (ppm) by the coefficient of the heat value for each compound [6]. Capsaicinoids main characteristic is specified binding to pain and heat receptors.

\footnotetext{
${ }^{1}$ Ach. Ferdiansyah Pradana P, Moch. Dimas Khoirul U, and Angga Septian E are with Departement of Chemical Engineering, Institut Technologi Sepuluh Nopember, Surabaya 60111, Indonesia. E-mail: ach_ferdi@chem-eng.its.ac.id; mochammaddimasku@gmail.com; anggaseptiane@gmail.com.
}

It can cause grave pain immediately after contact with the skin because of its direct action on sensory nerve fibres. Capsaicin has anti-mutagenic [7] and anti-carcinogenic properties, and has analgesic [8] and anti-inflammatory effects[9].

Today, researchers make innovations in technology for extracting capsaicin. Several methods developed to extract capsaicin from cayenne pepper are Soxhlet, Microwave Assisted Extraction (MAE) and Ultrasonic Assisted Extraction (UAE).

Much attention has been given to apply ultrasound for the extraction of natural products. Compared to conventional extraction, ultrasound- assisted extraction (UAE) permits to achieve complete extraction in shorter time, reduce solvent consumption, increase yield of extracted components and increase rate of extraction. The enhancement of UAE efficiency is attributed to a phenomenon of cavitations bubbles produced in the solvent as a respond to an ultrasonic wave. During expose to the wave, the cavitation bubbles are able to grow and finally collapse when they reach a critical point. The implosion of cavitation bubbles generates macroturbulence, high velocity inter-particle collisions and perturbation in micro-porous particles of solid material which accelerates internal diffusion. When these bubbles collapse onto the surface of a solid material, the bubbles release micro jets directed towards solid surface that result in surface peeling, erosion and particle breakdown which allowing higher penetration of the solvent into solid particles and the intracellular product compounds released by disrupting the cell walls.

A great performance was reported in application of UAE to extract herbal, oil, protein and bioactive and functional compounds e.g. polyphenolics, anthocyanins, aromatic compounds, polysaccharides from variety of matrices such as plant and animal materials [10]. 
Moreover, it was reported that applications of UAE improved the extraction yield of bioactive compounds by 6-35\% compared to conventional process [11], [12].

The most optimum method to extract capsaicin was UAE, because this method produced high cocentration of capsaicin with low energy consumption [13]. But UAE technology produced lower yield than Soxhlet dan MAE. Then, Developed the latest method namely Pressurized Hot Water Extraction (PHWE) which uses water as the solvent [14]. From this study, capsaicin produced greater yields than three other methods studied. But in its application, that method requires high cost and very complicated operational, because it needs high temperature and pressure as well as substantial operational tools.

From all of the methods, MAE is the most common method which is used because it needs short operation time, low-energy consumption, and easy to do. But, the yield production is still low. Therefore, in this research, ultrasonic wave was added as an innovation which was called Ultrasonic Extraction-Microwave Distillation for producing high yield, high concentration and low-cost operation.

\section{METHOD}

\section{A. Materials}

The materials used were cayenne pepper (Capsicum frutescens) is dried to a moisture content of 9\%. Ethanol $96 \%$, ethanol p.a and Asetronitril were purchased from Merck, Sodium Metabisulfit $\left(\mathrm{Na}_{2} \mathrm{~S}_{2} \mathrm{O}_{5}\right)(2 \%)$ and Acetic acid $(1 \%)$. The reference standard of capsaicin (97\%) was obtained from Sigma, Singapore.

\section{B. Tools}

The tools used in this research are ultrasonic scaler and microwave. Ultrasonic scaler is used to extract the capsaicin compound. Specification of the ultrasonic scaler with a frequency of $30+/-3 \mathrm{kHz}, 220-240$ Volt input supply power, and 3-30 Watt output power. Microwave is used as a heat producer in the distillation process. Specification of the microwave power is 400 watts (50A / $220 \mathrm{~V})$. HPLC on Agilent 1100 HPLC system and 1100 ChemStation software. Sample analyses were performed Merck LiChrospher 100 RP-18. Ultrasonic Extraction Microwave Distillation (USE-MD) tool series can be seen in Figure 1.

\section{Experimental Design}

\section{1) Pretreatment Process}

The process was started by washing the chili as the raw material, then proceeded with bleaching process using $2 \%$ of Sodium Metabisulfit $\left(\mathrm{Na}_{2} \mathrm{~S}_{2} \mathrm{O}_{5}\right)$ in 1 liter of water at $90^{\circ} \mathrm{C}$.

\section{2) Mositure Content}

Samples studied were dried in an electrical oven before extraction as described: amounts of about $20 \mathrm{~g}$ of samples were placed on a desiccated in an electrical oven at $60{ }^{\circ} \mathrm{C}$ for $24 \mathrm{~h}$. After that it was cooled to room temperature in a desiccator before weighing. The above described procedure was repeated at every $2 \mathrm{~h}$ until the ratio $\mathrm{m} / \mathrm{m}(\%)$ was less than $10 \%$. then it was screened until it reached 100 mesh.

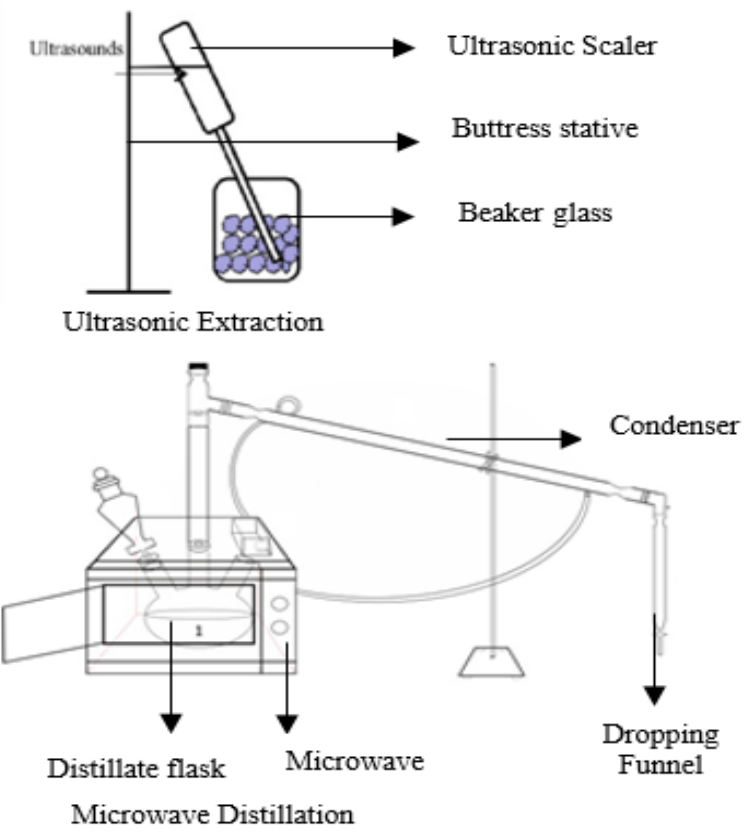

Figure 1. Ultrasonic Extraction Microwave Distillation (USE-MD) tool series

\section{3) Extraction Process}

The raw material was 20 grams of chili and the solvent was $500 \mathrm{ml}$ of ethanol $96 \%$. Extraction of chili was done by maseration and ultrasonic method in variable of time about 10, 20, 30, 40, and 50 minutes, followed by microwave distillation process for 30 minutes at $78^{\circ} \mathrm{C}$ in 1 atm so that the oleoresin capsaicin oil was obtained. Then it was poured into petri dish for drying process (to remove water and remaining ethanol) at $60^{\circ} \mathrm{C}$ in oven for 5 hours. Extractions performed, whatever the solvent and whatever the procedure used, were repeated at least three times. After the extraction, the extract was filtered and analyzed.

4) Analysis

The extract was analyzed to determine the yield and concentration of capsaicin using HPLC method. Yield of capsaicin was expressed as a percentage of the weight of capsaicin obtained after extraction relative to the weight of dry sample used for extraction, while quantitative analysis of capsaicin was carried out by HPLC on Agilent 1100 HPLC system composed of a quaternary pump Zwith a degasser, a thermostatted column compartment, a variable wavelength detector, an autosampler and 1100 ChemStation software. Sample analyses were performed Merck LiChrospher 100 RP-18 column ( 4.0 x $250 \mathrm{~mm} 5$ $\mu \mathrm{m})$ at a column temperature of $35^{\circ} \mathrm{C}$. The mobile phase was acetic acid $1 \%$ : Asetronitril (1:1) at a flow rate of 1,5 $\mathrm{ml} / \mathrm{min}$, and the effluent was monitored at $280 \mathrm{~nm}$ by UV detector and sample volume injected was $20 \mu 1$.

\section{RESULT AND DISCUSSION}

In this study effects of USE-MD and ME-MD methods to capsaicin yield, concentration and consumtion energy were studied A. Effect of USE-MD and MD-ME methods to Capsaicin
Yield 
In this research, the extraction process of capsaicin substance from cayenne pepper (Capsicum frustecens L.) fruit, using two methods: Ultrasonic Extraction -Microwave Distilation (USE-MD) and Maceration ExtractionMicrowave Distillattion (ME-MD). USE-MD is a method of extraction of materials dissolved or bioactive components in plants with the help of ultrasonic waves. This method is very easy to operate because it does not require supercritical and subcritical conditions (operating conditions of high temperature and pressure). USE-MD technology is very suitable for taking compounds that are thermolabil because it has better temperature control. From the result, the yield of capsaicin as in Table 1.

TABLE 1.

THE YIELD OF CAPSAICIN BY USING USE-MD AND ME-MD METHOD

\begin{tabular}{ccc}
\hline \hline \multirow{2}{*}{$\begin{array}{c}\text { Extraction time } \\
\text { ( minutes ) }\end{array}$} & \multicolumn{2}{c}{ Yield ( \% ) } \\
\cline { 2 - 3 } ( USE - MD ) & (ME-MD) \\
\hline 10 & 2.242 & 2.114 \\
20 & 2.508 & 2.267 \\
30 & 2.795 & 2.445 \\
40 & 2.765 & 2.568 \\
50 & 2.736 & 2.535 \\
\hline
\end{tabular}

From the Table 1, it can be seen that USE MD and MEMD methods increased yield in all variable of extraction times, but ultimately capsaicin yield declined slightly after reaching the optimum point at the time 30 and 40 minutes. To determine the optimum time of each method, the data can be described in the Figure 2.

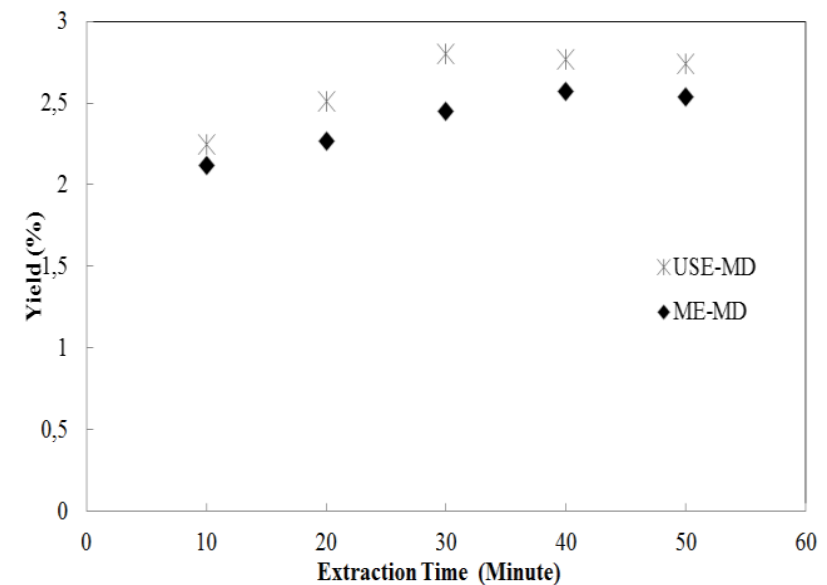

Figure 2. The yield of capsaicin by using USE-MD and ME-MD methods

Figure 2 showed that USE-MD method had higher average yield in all variables of extraction time compared with ME-MD method. For an example in 20 minutes, USEMD method produced yield about $2.508 \%$, while ME-MD method produced yield about $2.267 \%$. Similarly, in the extraction time of 40 minutes, USE-MD method produced a yield of $2.765 \%$, while ME-MD method produced a yield of $2.568 \%$. The yields of vanillin were comparables after one hour by UAE vs. $8 \mathrm{~h}$ in conventional extraction [15]. A fast UAE of capsaicinoids from pepper as also been set up by Barbero et al, who developed a reproducible ultrasonic extraction method using methanol as solvent

Our results explained that USE-MD method produced a higher yield than ME-MD method. Our results clearly show that ultrasound enhances the amount of capsaicin extracted and this can be attributed to an improvement in mass transfer because of the cavitation produced during the USEMD. Additionally, cell walls can be ruptured resulting in easier extraction of capsaicin into the solvent and the collapse of cavitation bubbles causes micro-jetting further enhancing dissolution

This extraction according into solid-liquid extraction. It is a mass transport phenomenon in which compounds in solid matrix migrate into solvent by diffusion and osmotic mechanism which induced by ultrasounds. Application of ultrasound in solid-liquid extraction forms cavitations bubbles which break the plant cells to facilitate penetration of solvent into the cells, it can be seen in Figure 3. The penetration facilitates swelling and hydration, causing an enlargement in the pores of the cell wall,which improves the diffusion process and leading to enhance mass transfer [16]. This result agreed that extraction time is an important variable in USE-MD of capsaicin compounds from plant materials. A longer extraction time permits more contact time for the cavitation bubbles to rupture more plant cells, result in an increase of the capsaicin extracted

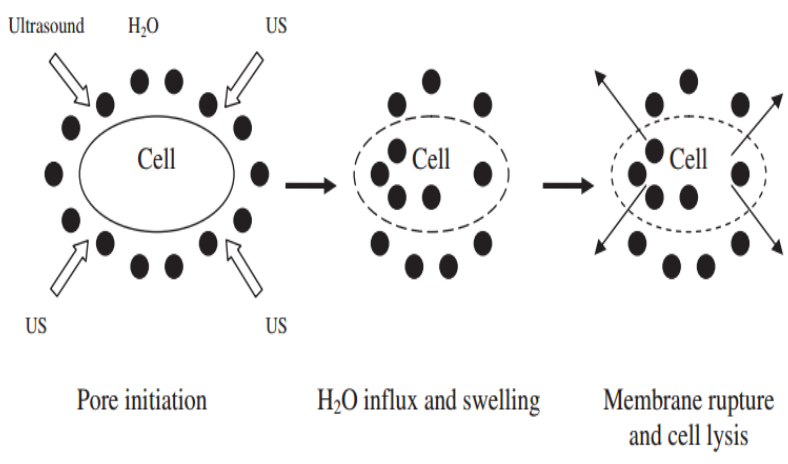

Figure 3. Mechanism of ultrasound-induced cell damage adapted from

To determine the optimum time of the both methods extraction, it can be seen in Figure 3.1. The optimum time for USE-MD method is 30 minutes with the yield about $2.795 \%$, while the optimum time for ME-MD method is 40 minutes with the yield about $2.568 \%$. This result showed that USE-MD method can increase the yield about $8 \%$ from ME-MD method with a shorter period of time. Moreover, USE-MD not only improved yields but as the method is fast and run at low temperature, the final product usually showed less thermal degradation than traditional methods.

Using USE-MD or ME-MD method increased yield of capsaicin result in all variables of extraction time, it can be seen in Figure 3.1, but in the end declined slightly. It is because concentration of capsaicin outside the cell after suffering an equilibrium point is higher than the concentration of capsaicin in the cell. The result is happening mass transfer process of capsaicin which have higher concentrations (outside the cell) to the lower concentration of capsaicin (in the cell). The kinetic of extraction is clearly increased which could be attributed to ultrasonic cavitation while it is the only variable added between both experiments. The beginning of the extraction, dissolution of soluble components on surfaces of the plant matrix occurs. This first stage results in a rapid increase of yield capsaicin. The next stage is mass transfer of the solute from the plant matrix into the solvent by diffusion 
and osmotic processes, which is slower process., so that there is not increasing of yield significantly, even if it is done up in a state of equilibrium, the solute will come back again into the cell.

Although USE-MD can be used successfully for extraction proposes, it should be borne in mind that longer ultrasonication time may lead to the destruction of bioactive compounds. It is also well known that ultrasound can lead to the production of free radicals within the cavitation bubbles and in some circumstances these free radicals can induce undesirable changes and /or destruction of the compounds extracted. A decrease on the levels of phytochemicals extracted from peanuts with longer ultrasonication times [17]. Our study showed that the treatment time affects the amount of capsaicin extracted.

\section{B. Effect Analysis USE-MD and MD-ME Method Against Capsaicin Concentration}

Determine the concentration of capsaicin, it should be analyzed by HPLC method. Concentration test of capsaicin is conducted to determine the cayenne pepper extract quality, because the higher of capsaicin concentration is the better quality of extract. Capsaicin concentration also show spicy flavor characteristic of chili. Therefore, it is necessary to analyze capsacin concentration of extraction. From the results, capsaicin concentration as follows in Table 2.

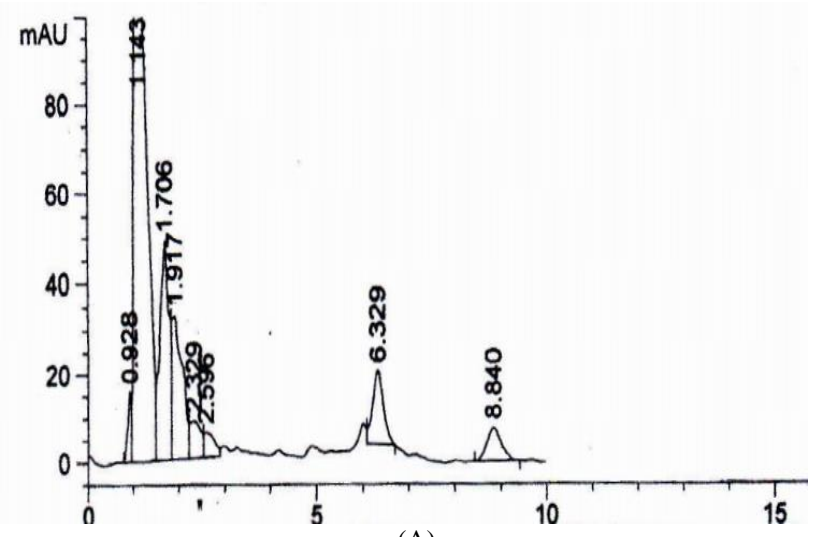

(A)

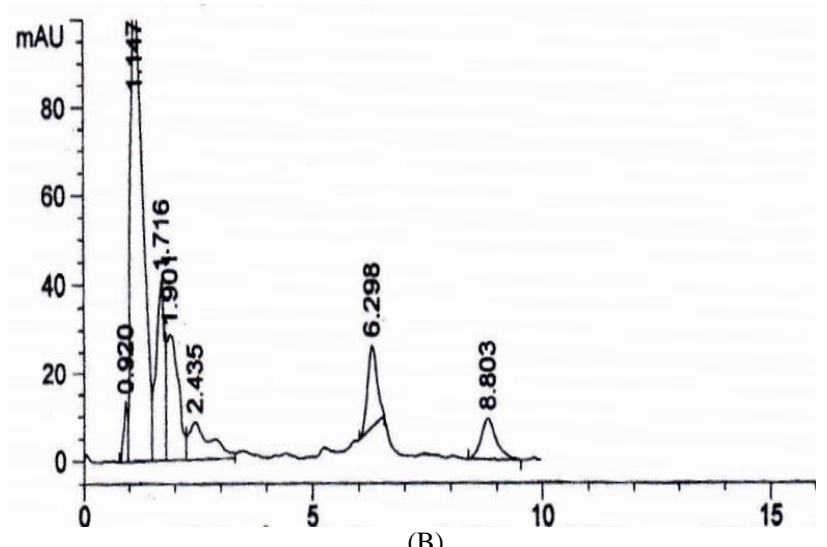

Figure 4. Area percent report for USE-MD method (A) and ME-MD method (B) used HPLC
TABLE 2

RESUlt CONCENTRATION TEST OF CAPSAICIN IN EACH METHOD

\begin{tabular}{cccc}
\hline \hline Method & $\begin{array}{c}\text { Concentration of } \\
\text { Capsaicin }(\% \text { w/w) }\end{array}$ & $\begin{array}{c}\text { Optimum } \\
\text { Yield }(\% \text { w/w) }\end{array}$ & $\begin{array}{c}\text { Optimum Time } \\
\text { (minutes) }\end{array}$ \\
\hline USE-MD & 0,294 & 2,795 & 30 \\
ME-MD & 0,285 & 2,568 & 40 \\
\hline \hline
\end{tabular}

The extraction by adding ultrasonic waves generate produce higher yield and relative concentration with a faster time than the conventional method (maceration) [18], [19]. It happened because the intensity of the ultrasonic waves propagate and carry energy. If the energy of the ultrasonic waves through a cell, then the wave will release heat energy and cause heating, tissue temperature will increase and then resulting cavitation effect, i.e. rupture of bubbles in a liquid. When the cavitation bubbles broke, the surface of the solid (cell wall) will be broken anyway, it causes the liquid (solvent) will easily fit into the cell nucleus. So the mass transfer process is higher.

In this case, there are two types of cavitational collapse that can affect the surface of solids (Figure 5) : (1) cavitational collapse on the surface of the solid due to the presence of surface defects entrapped gases or impurities; (2) cavitational collapse close to a surface causing a microstreaming of solvent to impinge on the surface (i.e. cleaning action of ultrasound). It has been observed that ultrasonic irradiation can cause particle rupture (i.e. disruption) which results in a decrease in particle size and an increase in surface area for reaction. Alternatively, cavitational collapse in a medium containing two immiscible liquids can cause the formation of an emulsion [20].

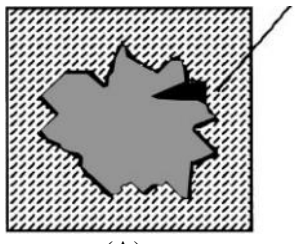

(A)

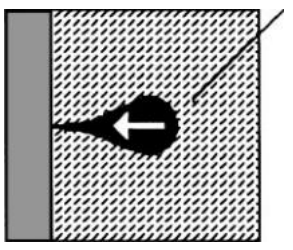

(B)
Trappd gas on surface or in defects cause nucleation and cavitational collapse resulting in fragmentation

Collapese near solid surface in the liquid phase causes microjet to hit surface

Figure 5. Cavitational effects at a solid liquid interface: (A) cavitational collapse on the surface of a solid particle; (B) cavitational collapse close to a surface of a solid particle. Adapted from [23]

Moreover, the maximum of concentration capsaicin in this research was lower than the concentration capsaicin. This is maybe, because of in this research used microwave distillation to separate ethanol from capsaicin with high electrical power as big as 400 Watt. It could be explained that at a higher electrical power, the rapid heat might have caused the degradation of capsaicinoids [21]. During irradiation, the plant cells were thermally stressed and the temperature of the cell wall was continuously rising. Consequently, the cell walls were ruptured and the 
extractant were thermally degraded. Therefore, the maximum electrical power without degradation of capsaicin

\section{Analysis of Energy Consumption and Costs by Using USE MD and ME-MD Method}

Determine the economic value from USE-MD and MEMD method, it is not only according to yield result, but also accounting energy consumption and cost value which need to extraction process.

TABLE 3.

ENERGY CONSUMPTION AND COSTS REQUIRED IN EACH METHODS

\begin{tabular}{lcc}
\hline \multirow{2}{*}{ Parameter } & \multicolumn{2}{c}{ Method } \\
\cline { 2 - 3 } & USE - MD & ME-MD \\
\hline Total Time (Minutes) & 60 & 70 \\
Total Input Power (Watt) & 730 & 700 \\
Capsaicin Mass (gram) & 0.832 & 0.741 \\
Price (Rp/g capsaicin) & 1188 & 1493 \\
\hline \hline
\end{tabular}

Table 3 showed comparison between energy consumption and costs for USE MD and ME-MD methods. For USEMD method in 60 minutes can produced capsaicin mass of 0.832 grams with a total input power of 730 watts, so the cost required to obtain 1 gram of capsaicin is Rp 1188 . While ME-MD method in 70 minutes was able to produce capsaicin mass amounted to 0.741 grams with a total input power of 700 watts, so the cost required to obtain 1 gram of capsaicin is Rp 1493. It explains that the USE-MD method gave the minimum energy and low cost than ME-MD method. USE-MD method was choosen because it is shorter and more efficient, about $20.4 \%$, than ME-MD. Therefore, the optimum technique for the capsacin extraction was using USE-MD method in 60 minutes to reduce the energy consumption and low cost during the extraction process.

\section{CONCLUSIONS}

The result showed that the best method to produce capsaicin extract from cayenne pepper (Capsicum frustecens $\mathrm{L}$.) was USE-MD method in 30 minutes. This method gave yield of 2,795\% with concentration of capsaicin about $0,294 \pm 0,02 \% \mathrm{lb} / \mathrm{lb}$. Respectively, USEMD required minimum energy consumption and was evaluated as an idealistic method.

\section{ACKNOWLEDGEMENTSS}

The authors are grateful to KEMENRISTEK DIKTI (Research and Community Servece, Directorate General of Higher Education) for the fincancial support for this research.

\section{REFERENCES}

[1] BADAN KETAHANAN PANGAN KEMENTERIAN PERTANIAN, "Data Statistik Ketahanan Pangan Tahun 2014 Badan Ketahanan Pangan,” 2015.

[2] T. H. C. Dewi, L. U. Khasanah, and Kawiji, "Optimasi Ekstraksi Oleoresin Cabai Rawit Hijau (Capsicum Frutescens L.) Melalui Metode Maserasi," vol. 1, no. 1, 2012.

[3] M. A. Bernal, A. A. Calderon, M. A. Pedreno, R. Munoz, A. R. Barcelo, and F. M. de Caceres, "Capsaicin oxidation by peroxidase from Capsicum annuum (variety Annuum) fruits," J. Agric. Food
Chem., vol. 41, no. 7, pp. 1041-1044, 1993.

[4] G. F. Barbero, J. M. G. Molinill, R. M. Varela, M. Palm, F. A. Macía, and C. G. Barroso, "Application of Hansch's Model to Capsaicinoids and Capsinoids: A Study Using the Quantitative Structure-Activity Relationship. A Novel Method for the Synthesis of Capsinoids," J. Agric. Food Chem., vol. 58, pp. 3342-3349, 2010.

[5] G. F. Barbero, A. Liazid, M. Palma, and C. G. Barroso, "Ultrasound-assisted extraction of capsaicinoids from peppers," Talanta, vol. 75, no. 5, pp. 1332-1337, 2008.

[6] H. T. Huynh and R. W. Teel, "In vitro antimutagenicity of capsaicin toward heterocyclic amines in Salmonella typhimurium strain TA98," Anticancer Res., vol. 25, no. 1 A, pp. 117-120, 2005.

[7] P. Anandakumar, S. Kamaraj, S. Jagan, G. Ramakrishnan, and T. Devaki, "Capsaicin provokes apoptosis and restricts benzo(a)pyrene induced lung tumorigenesis in Swiss albino mice," Int. Immunopharmacol., vol. 17, no. 2, pp. 254-259, 2013.

[8] C. H. Martini et al., "A novel approach to identify responder subgroups and predictors of response to low- and high-dose capsaicin patches in postherpetic neuralgia.," Eur. J. Pain, vol. 17, no. 10, pp. 1491-1501, Nov. 2013.

[9] N. Ercan, M. O. Uludag, E. R. Agis, and E. Demirel-Yilmaz, "The anti-inflammatory effect of diclofenac is considerably augmented by topical capsaicinoids-containing patch in carrageenan-induced paw oedema of rat," Inflammopharmacology, vol. 21, no. 6, pp. 413-419, 2013.

[10] D. H. Wardhani, D. K. Sari, and A. Prasetyaningrum, "Ultrasonicassisted extraction of antioxidant phenolic compounds from Eucheuma cottonii," Reaktor, vol. 14, no. 4, 2013.

[11] F. Chemat, Zill-e-Huma, and M. K. Khan, "Applications of ultrasound in food technology: Processing, preservation and extraction," Ultrason. Sonochem., vol. 18, no. 4, pp. 813-835, 2011.

[12] K. Vilkhu, R. Mawson, L. Simons, and D. Bates, "Applications and opportunities for ultrasound assisted extraction in the food industry - A review," Innov. Food Sci. Emerg. Technol., vol. 9, no. 2, pp. 161-169, 2008.

[13] S. Chuichulcherm, S. Prommakort, P. Srinophakun, and A. Thanapimmetha, "Optimization of capsaicin purification from Capsicum frutescens Linn. with column chromatography using Taguchi design," Ind. Crops Prod., vol. 44, pp. 473-479, 2013.

[14] T. Bajer, P. Bajerová, D. Kremr, A. Eisner, and K. Ventura, "Central composite design of pressurised hot water extraction process for extracting capsaicinoids from chili peppers," J. Food Compos. Anal., vol. 40, pp. 32-38, 2015.

[15] D. Jadhav, R. B.N., P. R. Gogate, and V. K. Rathod, "Extraction of vanillin from vanilla pods: A comparison study of conventional soxhlet and ultrasound assisted extraction," J. Food Eng., vol. 93, no. 4, pp. 421-426, 2009.

[16] M. Bilgin and S. Sahin, "Effects of geographical origin and extraction methods on total phenolic yield of olive tree (Olea europaea) leaves," J. Taiwan Inst. Chem. Eng., vol. 44, no. 1, pp. 812,2013

[17] Y. C. Chukwumah, L. T. Walker, M. Verghese, and S. Ogutu, "Effect of frequency and duration of ultrasonication on the extraction efficiency of selected isoflavones and trans-resveratrol from peanuts (Arachis hypogaea)," Ultrason. Sonochem., vol. 16, no. 2, pp. 293-299, 2009.

[18] W. Yang, V. K. Ajapur, K. Krishnamurthy, H. Feng, R. Yang, and T. M. Rababah, "Expedited extraction of xylan from corncob by power ultrasound," Int. J. Agric. Biol. Eng., vol. 2, no. 4, pp. 76-83, 2009.

[19] L. Zhang, Y. Shan, K. Tang, and R. Putheti, "Ultrasound-assisted extraction flavonoids from Lotus ( Nelumbo nuficera Gaertn ) leaf and evaluation of its anti-fatigue activity," vol. 4 , no. 8, pp. 418422, 2009.

[20] C. Bendicho and I. Lavilla, "EXTRACTION | Ultrasound Extractions," in Reference Module in Chemistry, Molecular Sciences and Chemical Engineering, 2013.

[21] S. Chemat, H. Ait-Amar, A. Lagha, and D. C. Esveld, "Microwaveassisted extraction kinetics of terpenes from caraway seeds," Chem. Eng. Process. Process Intensif., vol. 44, no. 12, pp. 1320-1326, 2005. 